\title{
Climatic change: CD-Links special issue on national low-carbon development pathways
}

\author{
Roberto Schaeffer ${ }^{1} \cdot$ V. Bosetti ${ }^{2} \cdot$ E. Kriegler ${ }^{3} \cdot$ K. Riahi $^{4} \cdot$ D. van Vuuren ${ }^{2}$
}

Published online: 17 October 2020

(C) Springer Nature B.V. 2020

\section{Objective and motivation}

One hundred and ninety-three governments adopted the Paris Agreement on Climate Change in 2015. The agreement foresees, for the near term, a new bottom-up process where countries pledge so-called nationally determined contributions (NDCs) for reducing their greenhouse gas (GHG) emissions by 2025-2030. At the same time, the Paris Agreement defines the longterm objective to hold temperature change to well below $2{ }^{\circ} \mathrm{C}$ and to pursue efforts to limit it further to $1.5^{\circ} \mathrm{C}$. The consistency between the NDCs and the long-term temperature goals is planned to be regularly assessed in global stocktaking exercises as part of the international negotiations. At the same time, countries have also committed themselves to implement a set of Sustainable Development Goals (SDGs) in order to eradicate poverty, protect the global environment and spur inclusive economic development. Within this context, the CD-LINKS project (www.cd-links.org) brought together an international team of researchers with global, national and sectoral expertise to explore possible linkages between national and global pathways consistent with the overall objective of the Paris Agreement and sustainable development. Part of this work is summarised in this special issue in Climatic Change, which contains eleven papers, including this introductory one, presenting the insights from the collaboration between national and global modelling teams and yielding a more coherent and detailed picture of the future than is typical of climate change mitigation pathways studies focusing on the global level only.

This article is part of a Special Issue on "National Low-Carbon Development Pathways" edited by Roberto Schaeffer, Valentina Bosetti, Elmar Kriegler, Keywan Riahi, Detlef van Vuuren, and John Weyant

Roberto Schaeffer roberto@ppe.ufrj.br

1 Centre for Energy and Environmental Economics, Energy Planning Program, CENERGIA/PPE/ COPPE/UFRJ, Centro de Tecnologia, Bloco C, Sala C-211, Cidade Universitária, Ilha do Fundão, Rio de Janeiro, RJ 21941-914, Brazil

2 Centro Euro-Mediterraneo sui Cambiamenti Climatici (CMCC), Lecce, Italy

3 Potsdam Institute for Climate Impact Research (PIK), Potsdam, Germany

4 International Institute for Applied Systems Analysis (IIASA), Laxenburg, Austria 
The special issue brings together national research teams from Brazil, China, EU, India (two teams), Japan (two teams), Russia and the USA, and explores the transformational impacts of the NDCs on the GHG emissions and underlying socioeconomic systems. A distinctive feature of the papers is that they are based on an iterative dialogue between global and national research teams and stakeholders, identifying viable scenarios at the national level that are also coherent and consistent globally. Through this process, sustainable pathways for strengthening the NDC ambition consistent with the $1.5-2{ }^{\circ} \mathrm{C}$ objective are developed. While previous studies have primarily explored the implications of cumulative $\mathrm{CO}_{2}$ emissions budgets at the global scale, the combination of national low-carbon development pathways within a long-term global transformation framework towards a $1.5-2{ }^{\circ} \mathrm{C}$ world has received far less attention so far.

This special issue is also timely since some of the results presented here are expected to provide critical inputs to the forthcoming Sixth Assessment Report of the Intergovernmental Panel on Climate Change (IPCC AR6). At the heart of this special issue are globally consistent national $\mathrm{CO}_{2}$ budgets for the near and long term. The papers in this special issue show a diversity of national approaches, based on differences across countries with respect to the availability of mitigation technologies, the investment and finance needs for deploying and upscaling these technologies, and the regional (near-term) gaps between current policies and the aspiration implied by the long-term objective of $1.5-2{ }^{\circ} \mathrm{C}$. Importantly, this also includes a critical assessment of whether current policies are on track for achieving the NDCs, as well as discussions on the implications of different effort-sharing approaches for the national carbon budgets and emission pathways. The resulting scenarios assess viable strategies to ratchet up the NDCs in order to make them more consistent with the long-term $1.5-2{ }^{\circ} \mathrm{C}$ objective, subject to different burden-sharing schemes.

The country studies also explore national development pathways consistent with local development goals (e.g., for poverty eradication or local air pollution). These studies benefit particularly from the much greater granularity of integrated national/regional models to explore low-carbon development pathways that ensure the achievement of a wide range of local sustainable development objectives.

The two first papers in the special issue take a multi-national perspective. While the first paper provides an overview and a comparative assessment of the effort across different countries, the second paper explores the ethical implications of the scenarios by comparing the implied national carbon budgets with the outcomes of different burden-sharing mechanisms from the literature. Subsequently, eight papers look into national transformation pathways for Brazil, China, EU (as a block), India (two papers), Japan, Russia and the USA, as is described in more detailed below.

\section{The papers of this special issue}

Below, we briefly summarise the papers in the special issue - indicating also the key relationships between them.

\subsection{Comparing transformation pathways across different regions and countries}

Schaeffer et al. (2020, this issue) explore the consequences of different policy assumptions and the derivation of globally consistent, national low-carbon development pathways for the seven 
largest GHG-emitting countries (EU28 as a bloc) in the world. They introduce the overall methodology for developing pathways used throughout papers included in the special issue, discussing the process by which global integrated assessment model (IAM) teams in the CDLinks project interacted and derived boundary conditions in the form of carbon budgets for the different countries. Carbon budgets derived for the different countries as a result of global IAM runs for the 2011-2050 period were then used in eleven different national energy-economy models and IAM for deriving low-carbon pathways for the seven countries in line with a well below $2{ }^{\circ} \mathrm{C}$ world up to 2050 . The paper concludes by presenting a comparative assessment of the resulting pathways and of the challenges and opportunities associated with them, with results indicating quite different mitigation pathways for the different countries in terms of emissions reductions split by sectors and technological alternatives.

\subsection{Implication of various effort-sharing approaches for regional carbon budgets and emission pathways}

Van den Berg et al. (2019, this issue) explore how different country-level emission targets and carbon budgets can be derived based on equity ("fairness") principles. The authors apply novel methods directly based on the global carbon budget and compare them with national carbon budgets derived from least-cost emissions pathways. The different approaches discussed in the paper are as follows: equal cumulative per capita emissions, contraction and convergence, grandfathering, greenhouse development rights and ability to pay. The paper greatly benefits from the wide authorship from a range of countries included in CD-Links project to determine default settings and sensitivity analyses which are critical for the meaningfulness of the results. In the end, results provide a clear overview of the effects of equity principles on how much each country "should" contribute to climate change mitigation, helping to put the CD-Links project pathways into the perspective of different burden-sharing mechanisms that have been proposed over the last years.

\subsection{Brazil emission trajectories in a $2^{\circ} \mathrm{C}$ world: the role of disruptive technologies versus land-based mitigation in an already low-emission energy system}

In this paper, Köberle et al. (2020, this issue) analyse Brazil's role in global efforts to address climate change within the modelling framework of the CD-Links project. The Brazil Land-Use and Energy Systems (BLUES) model is used to produce emissions scenarios for Brazil for the 2011-2050 period according to the project's protocol. The scenarios' results highlight important interplays between the AFOLU and energy sectors in Brazil, illustrating trade-offs between land-based mitigation and biofuel production in the country.

\subsection{Modelling of power sector decarbonisation in China: comparisons of early and delayed mitigation towards 2-degree target}

In this paper, Wang et al. (2019, this issue), using the China-Times model to run climate mitigation scenarios, examine the impact of early and delayed mitigation efforts for the power sector in China for the period 2011-2050. Results indicate, among other things, that in the most ambitious scenarios, the Chinese power sector achieves net negative emissions by midcentury, and that rapid phase-out of coal-fired power plants, deployment of bioenergy with 
carbon capture and sequestration (BECCS) and acceleration in the deployment of renewable energy will be a key to achieve this goal.

\subsection{Energy system transition and macroeconomic impacts of a European decarbonisation action towards a below $2{ }^{\circ} \mathrm{C}$ climate stabilisation}

In this paper, Vrontisi et al. (2019, this issue) explore different EU28 emission mitigation pathways in the context of a well below $2{ }^{\circ} \mathrm{C}$ global climate stabilisation target and look at possible macroeconomic impacts by considering various levels of climate action by major non-EU emitters. The study relies on the use of the technology-rich energy system model PRIMES and the global large-scale hybrid computable general equilibrium model GEM-E3. These two models are soft-linked to guarantee a consistent and robust framework for the analysis. Results indicate that the impacts on the EU28 economy are very much a function of the level of mitigation actions undertaken in other parts of the world and by the relative carbon intensity across regions.

\subsection{Energy system transformation to meet INDC, $2{ }^{\circ} \mathrm{C}$ and $1.5{ }^{\circ} \mathrm{C}$ targets for India}

In this paper, Vishwanathan and Garg (2020, this issue) develop a quantitative assessment of India's energy system efforts for meeting carbon mitigation commitments compatible with India's INDC and with a $2{ }^{\circ} \mathrm{C}$ and $1.5^{\circ} \mathrm{C}$ worlds, while achieving national sustainable development goals. Energy transformation trajectories are investigated under five different scenarios synchronised with climate mitigation regimes up to 2050 using a bottom-up optimisation model (AIM/Enduse). The authors conclude that the preparation of India's energy system for a deep decarbonisation future without compromising the country's national sustainable development goals will require major transformations already during the next 10 years.

\subsection{India's energy sector choices-options and implications of ambitious mitigation efforts}

In this paper, Mathur and Shekhar (Mathur and Shekar 2020, this issue) examine different mitigation scenarios for India's energy sector in order to analyse the implications on overall emissions intensity, costs, sectoral energy mix and technology choices. The analysis indicates that a multitude of actions would need to be undertaken across sectors for India to move forward towards its NDC targets and beyond. Key messages include the identification of sectors and technologies most relevant for ratcheting up India's NDC, the nature of barriers the country faces in transitioning to more stringent budgets, and finally the need for focusing on potential infrastructural and technology lock-ins in its transition story. In a similar vein of the previous study, the authors here also conclude that stringent emission mitigation in the case of India imply in the adoption of the right development strategies for the country sooner rather than later.

\subsection{Mid-century emission pathways in Japan associated with the global $2{ }^{\circ} \mathrm{C}$ goal: national and global models' assessments based on carbon budgets}

In this paper, Oshiro et al. (2019, this issue) investigate Japan's mid-century, low-emission carbon mitigation pathways using national and global IAMs in a common mitigation scenario 
framework relying on the carbon budgets corresponding to a global $2{ }^{\circ} \mathrm{C}$ goal, based on the cost-effectiveness allocation performed by the global models. Whereas models deployed here differ in the type of energy sources on which they foresee Japan basing its decarbonisation process, the multiple Japanese teams involved in this effort compared their results and showed that the large-scale deployment of low-carbon energy is always shared across most models in the different budget scenarios explored in this work.

\subsection{The low-carbon development options for Russia: business-as-usual or the breakthrough to deep decarbonisation}

In this paper, Safonov et al. (Safonov et al. 2020, this issue) explore different low-carbon mitigation options, from business-as-usual to active decarbonisation scenarios for Russia up to 2050. The authors show that decarbonisation efforts in the global economy may translate for Russia into a dilemma on whether to continue to rely on a fossil fuel-based and energyintensive growth or to join the rest of the world and switch to renewable energy sources and invest more in advanced, innovative energy technologies. The authors conclude that the key sectors of buildings, energy, industry and transport can all play a substantial role in decarbonising Russia's economy, but the country's historical reliance on domestic consumption and exports of fossil fuels creates strong barriers for that.

\subsection{US energy system transitions under cumulative emission budgets}

In this paper, Feijoo et al. (2020, this issue), employing the GCAM-USA model, investigate the implications of cumulative carbon dioxide emissions budgets for the USA consistent with global 1.5 and $2{ }^{\circ} \mathrm{C}$ long-term temperature goals on the country's energy system through 2050 . There results indicate that increased ambition in the near term is a key in setting the stage for less disruptive transformations in the future to achieve more restrictive carbon dioxide emission budgets.

\section{Final considerations}

Together, the papers in this special issue provide a unique overview of national pathways aligned with the Paris Ambition. Clearly, the analysis was performed before the 2020 COVID-19 pandemic. Still, at a time when this virus is turning the world upside down, this special issue could not be more timely. After the first death recorded in China on January 9th, 2020, the COVID-19 crossed the planet and has affected the entire world, leading, in a first moment, to the confinement of billions of people in their homes, with implications that are still difficult to anticipate. The papers in the special issue are relevant to the current crisis in two ways.

First, there are clear parallels between the pandemic itself and climate change that allows us to draw interesting reflections. Both problems bring forward the clash between collective risks and individual action.

If we do not change our development pathways, we expect significant impacts to the part of the population that is more vulnerable: the poorest people of the poorest countries. The response to the pandemic has shown that in several parts of the world, collective action is possible (Hale et al. 2020). 
However, the pandemic is different in many crucial ways, particularly with respect to its visibility and its potential long-term solution. The effect of the COVID-19 is visible much more directly than the effect of the current climate crisis which enfolds at a much slower pace. In addition, and depending on how we react to global warming, we might reach a stage of the climate transformation for which there is no vaccine, and no return. In this sense, it is important that any economic recovery efforts and stimulus packages to deal with the still unfolding COVID-19 crisis are architecture in such a way as to try to refrain from producing massive potential emission rebounds that could result as a consequence of a return to a business as usual world in the energy and land-use systems (Nature Energy 2020).

By presenting a process whereby national objectives can be brought together and harmonised with global objectives, this set of paper provides a template for scenario-based policy-making that can be applied to other supranational crisis.

The second point is that countries have started to implement recovery packages in order to respond to the economic crisis that has followed the pandemic. The financial pledges made by different governments are large with major implications also for the "recovery" of GHG emissions. Governments now have thus the choice how to invest these funds, and whether to spur conventional fossil-based development, or to shift development towards a more sustainable direction. The pathways described in this special issue provide critical guidance on the order of magnitude of change, the pace and nature of the policy effort in order to achieve the latter.

That is why, we invite the readers of this special issue to learn more about the groundbreaking work presented in the pages that follow, which hopefully may help us solve the dilemma that is in front of us.

Acknowledgements We thank all CD-LINKS project partners for contributing to scenario development. Results presented here are not automatically endorsed by CD-LINKS project partners.

Authors' contributions RS coordinated the analyses and writing of this paper, to which all authors contributed. Also, all authors acted as guest editors to this special issue.

Funding This manuscript benefited from the financial support of the European Commission via the Linking Climate and Development Policies-Leveraging International Networks and Knowledge Sharing (CD-Links) project, financed by the European Union's Horizon 2020 research and innovation programme under grant agreement no. 642147 (CD-Links).

\section{References}

Feijoo F, Iyer G, Binsted M et al (2020) US energy system transitions under cumulative emissions budgets. Climatic Change (this issue). https://doi.org/10.1007/s10584-020-02670-0

Hale T, Webster T, Petherick A, Phillips T, Kira B (2020) Oxford COVID-19 government response tracker, Blavatnik School of Government

Köberle AC, Rochedo P, Lucena AFP, Szklo A, Schaeffer R (2020) Brazil emissions trajectories in a well-below $2{ }^{\circ} \mathrm{C}$ world: the role of disruptive technologies versus land-based mitigation in an already low-emission energy system. Climatic Change (this issue). https://doi.org/10.1007/s10584-020-02856-6

Mathur R, Shekar S (2020) India's energy sector choices - options \& implications of ambitious mitigation efforts. Climatic change (this issue). https://doi.org/10.1007/s10584-020-02885-1

Nature Energy (2020) Editorial: Recovering fast and slow. Nature Energy 5:273. https://doi.org/10.1038/s41560020-0614-9

Oshiro K, Gi K, Fujimori S, van Soest HL, Bertram C, Després J, Masui T, Rochedo P, Roelfsema M, Vrontisi Z (2019) Mid-century emission pathways in Japan associated with the global $2^{\circ} \mathrm{C}$ goal: national and global 
models' assessments based on carbon budgets. Climatic Change (this issue). https://doi.org/10.1007/s10584019-02490-x

Safonov G, Lugovoy O, Potashnikov V (2020) The low carbon development options for Russia: business-asusual or the breakthrough to deep decarbonisation. Climatic change (this issue). https://doi.org/10.1007 /s10584-020-02780-9

Schaeffer R, Köberle A, van Soest HL et al. (2020) Comparing transformation pathways across major economies. Climatic Change (this issue). https://doi.org/10.1007/s10584-020-02837-9

van den Berg NJ, van Soest HL et al (2019) Implications of various effort-sharing approaches for national carbon budgets and emission pathways. Climatic Change (this issue). https://doi.org/10.1007/s10584-019-02368-y

Vishwanathan SS, Garg A (2020) Energy system transformation to meet INDC, $2^{\circ} \mathrm{C}$ and $1.5^{\circ} \mathrm{C}$ targets for India, climatic change (this issue). https://doi.org/10.1007/s10584-019-02616-1

Vrontisi Z, Fragkiadakis K, Capros P, Kannavou M (2019) Energy system transition and macroeconomic impacts of a European decarbonization action towards a below $2^{\circ} \mathrm{C}$ climate stabilization, Climatic Change (this issue). https://doi.org/10.1007/s10584-019-02440-7

Wang H, Chen W, Zhang H, Li N (2019) Modeling of power sector decarbonisation in China: comparisons of early and delayed mitigation towards 2-degree target. Climatic Change (this issue). https://doi.org/10.1007 /s10584-019-02485-8

Publisher's note Springer Nature remains neutral with regard to jurisdictional claims in published maps and institutional affiliations. 